\title{
Introduction: innovation - from the forbidden to a cliché
}

Benoît Godin and Dominique Vinck

The study of innovation has become an industry. Hundreds of studies on the subject have been published in the last few decades. Theories, models, frameworks and narratives of innovation abound, competing among themselves for authority. It was possible to write reviews of the field 25 years ago. Today, it is nearly impossible for even the most knowledgeable researcher. The literature is too voluminous. To be sure, reviews and handbooks appear regularly. Yet they remain selective and reflect specific disciplinary boundaries (management, economics, science policy, sociology, psychology) or thematic orientations (human resources, managerial tools, skills, financing, entrepreneurship and so on).

Despite the differences, the studies produced in the last 65 years offer a relatively consistent view of innovation. Sociologist Everett M. Rogers has called this view the 'pro-innovation bias'. Innovation is good, always good:

Researchers have implicitly assumed that to adopt innovations is desirable behavior [rational] and to reject innovations is less desirable [irrational]. (Rogers, 1962, p. 142)

Rogers is not alone. In the 1960s and later, many researchers thought similarly:

The most outstanding feature of innovation is its mysteriousness ... Many problems arise in defining innovation ... because of the value judgment attached to the term ... The difficulty here is that most of us expect an innovation to be something good. (Knight, 1967, p. 478)

One of the vogue words these days is innovation. For some people it is even more - it is a value word that implies something good and positive. (Holt, 1971, p. 235)

Innovation tends to be viewed in positive terms socially. It is a good thing to advocate and to participate in. For the most part, researchers have assumed that innovation is good, and have sought to determine the conditions under 
which innovation takes place, the conditions that facilitate its diffusion, and the characteristics which distinguish more innovative individuals, groups and organizations from less innovative ones. One implicit assumption appears to be that research should foster innovation ... Rarely if ever is not adopting an innovation considered to be a possibly important, adaptive strategy. (Kimberly, 1981, pp. 84-5, 88)

How does this bias manifest itself in the literature? In 1969, Bela Gold, professor of industrial economics at Case Institute of Technology, summarized the literature on technological innovation, and called the shared assumptions in the field a 'guiding' or 'synoptic model' that reflects 'essentially similar, though unstated, conceptions of the basic system of relationships involved in [the field]' (Gold, 1969, p. 392). 'Taken together, these building blocks yield a model which combines the appeals of simplicity, rationality and seeming relevance both to widespread interpretations of recent business experience and to common conceptions of the decisionmaking processes of management' (Gold, 1969, p. 393-4). The four building blocks or assumptions are: technological innovations are inherently attractive; are generally the product of processes that are planned; are generated through a chain of essentially rational decisions; R\&D constitutes the most important means to technological innovation. ${ }^{1}$

As a consequence, theorists concentrate on the study of innovators, with little if any attention to the laggards and the non-innovators. They study the originators of innovation, relegating imitators to a minor or rather non-innovative role. They downplay opposition and resistance to innovation as irrational. They fail to perceive the rationale or strategies of noninnovators. Theorists actively promote innovation policies by consulting with governments and international organizations, among others, contributing to making innovation a panacea for every socioeconomic problem, with little analysis of what these problems are, and of what the collateral impacts of the innovation would be.

In all these efforts, the theorists have come together in defining what innovation is, contributing to the construction of a dominant representation of innovation as technological and industrial, and as good for the economy and the society. Theorists have also constructed several concepts appropriate to this representation, many of which have become catchwords or buzzwords. Studies of social innovation have not really changed the conventional theoretical framework and conceptual tools. What has been left out?

This book examines innovation from a different perspective. It deals with phenomena that have been amply discussed in the literature, but with a few exceptions rarely taken seriously by scholars of innovation: resistance to innovation, non-adoption, sluggishness of innovators, imitation, 
non-users, failure, outlaw innovation, unintended consequences, maintenance of (existing) innovation, non-innovators, de-adoption, slow innovation, innovation fads, re-shaping and adaptation of the innovation, rationale for not innovating, the social and political nature of innovation and so on.

Studies in the 1930s and 1940s on resistance to innovation were among the very first titles on innovation (Stern, 1937; Noss, 1940). Then in 1962, Everett Rogers drew an Innovation Use Tree that makes place for non-adoption and discontinuance of innovation in decisionmaking (Rogers, 1962, p.94). Several decades ago, some scholars also defined choosing not to innovate as a rational strategy, using different names like disinnovation (Eyestone, 1977) and exnovation (Kimberly, 1981). The persistence of failures has also been acknowledged for some time, but its study has been neglected except among a few scholars (for example, SPRU, 1972; Rubenstein et al., 1974; Utterback et al., 1976). It is interesting to cite a study here from the consulting firm Arthur D. Little Inc., the study that framed the influential US Department of Defense's project Hindsight, as well as its methodology and the later vocabulary on sources of information ('Events') in the 1960s. All of the innovations studied were successful weapon systems. Initially, it had been hoped to also study unsuccessful innovations. However, the Arthur D. Little report says: 'The very thought of gathering together such a body of information and stigmatizing it as characteristic of 'other', or 'unsuccessful' research and exploratory development met so much resistance that all attempts were abandoned very early in the project. Informally, it was made very clear to us by a number of people that it would be inexpedient to pursue this line at the present time' (Arthur D. Little Inc., 1965, 4.4-4.5).

It is one of the purposes of this book to assemble studies on these phenomena and examine them under the umbrella of NOvation. ${ }^{2}$ By NOvation we mean a series of phenomena and processes that could appear, within the dominant ideology and theories, as mindless, sub-rational, not seeing the common good in the innovation and forgoing opportunities. Facing considerable evidence associated with the innovation like the good arising from fast adoption, the perfection $a b$ initio of the innovation, we would like to shed light on processes like adaptation, withdrawal, learning from failure, alteration of the innovation and unintended consequences, and consider these processes as forms of innovation. 


\section{I.1 INNOVATION AS IDEOLOGY}

Today, the concept of innovation is wedded to an economic ideology, so much so that we forget that innovation has been a mainly political - and contested - concept for most of history. Before the twentieth century, innovation was a vice, something explicitly forbidden by law, the term used as a linguistic weapon by opponents of change. Innovation had nothing to do with creativity or technology, not yet. Innovation was whatever the opponent of change or the conservative called innovation (Godin, 2015a).

In contrast, today innovation is a word of honour. Everyone likes to be called an innovator; every firm innovates (or does it?); governments legislate to make whole nations innovative. As Jack Morton, engineer at Bell Laboratories, put it as early as 1971: 'Innovation is certainly a "buzz-word" today. Everyone likes the idea; everyone is trying to "innovate"; and everyone wants to do better at it tomorrow' (Morton, 1971, p. 73).

Innovation is a concept of mobilization. It serves a diversity of actors whose aim is to create communities and nations of innovators. On the theoretical side, innovation has become a bridging concept. It brings different disciplines together for the construction and study of a transdiscursive object.

When, why and how did the concept of innovation change its meaning? The change occurred gradually over the last 200 years. Innovation acquired a positive connotation because of its instrumental function in the political, social and material progress of societies. From the early nineteenth century on, a whole vocabulary developed that tells a story that creates and even sanctifies a progressive future, rehabilitating what were until then dirty words - like revolution - and adding new ones - like creativity - to talk of and about innovation. From that time on, innovation became a catchword that everyone understood spontaneously - or thought they understood; that every theorist talked about; that every government espoused.

Technology is part of the explanation. After World War II, those who contested innovation in the past - governments - start de-contesting innovation, and produced insightful thoughts on innovation as a policy tool. One after another, international organizations and governments embraced innovation as a solution to economic problems and international competitiveness, and then launched innovation policies. Scholars followed. At that precise moment, the dominant representation of innovation shifted to that of the economy: technological innovation - a phrase that emerged after World War II - as commercialized invention. Technological innovation serves economic growth. A whole new set of arguments developed: research and development (R\&D) leads to innovation and innovation to prosperity. Statistics are developed to support the idea: innovation 
surveys are administered to firms and the numbers collected into 'innovation scoreboards' that serve as so-called evidence-based information for policy-makers. Innovation becomes a basic concept of economic policy. In a matter of decades, science policy shifted to become innovation policy, and indicators on science and technology were relabelled as innovation indicators. In all these efforts, governments were supported by academics as consultants who imagined models of innovation by the dozens as a way to frame and guide policies. Model itself became an integral concept in the literature on innovation.

Technological innovation has become an uncontested value. The debates on technology were conducted before the concept of innovation came into vogue, namely, within the literature on 'technological change' (that is, technological unemployment). These debates were settled with optimism in the first half of the twentieth century, leaving technological innovation free from real contestation (Godin, 2017). This points to an important question. What is technological innovation, and how is it distinct from other concepts like technology and technological change?

Before the twentieth century, technology was understood as a body of knowledge concerning the practical arts. This meaning has shifted over the last century to technology as a good or product (Schatzberg, 2006), with scholars emphasizing the generation of technology rather than technology in use or its diffusion (Edgerton, 2008). Technological change as a precursor term to technological innovation refers to many things, but principally to new techniques, their use in industrial production, and the study of their impacts on society (Godin, 2015b). Technological innovation is considered today a process concerned with the commercialization of new goods or inventions, from invention to diffusion (Godin, 2016). This book concentrates on technological innovation and the literature dealing with the concept as such, particularly what some call 'innovation studies' (Godin, 2014). To a considerable extent, the book proposes an alternative reading of the latter.

\section{I.2 CHANGING THE APPROACH REGARDING INNOVATION}

Facing this ideology regarding innovation, the book focuses on both the literature and phenomena that have been left out, like imitation, resistance, discontinuance, disinnovation, failures, withdrawal and de-adoption. The book assembles studies on these neglected aspects of non-innovation in order to illuminate what we do not know about innovation. It offers a considered view of a major concept of society - innovation - and invites 
researchers to seriously pursue new avenues or develop more innovative thinking about innovation through a critique of current representations of innovation. The book critically examines dominant concepts, theories and policies on innovation, seeking alternative approaches. It renews our understanding of neglected approaches like mimetism, slow-down, voluntarily mistaking, maintenance of (existing) innovation, regulatory enforcement and seeking alternative options.

The book has four parts that emerge from narratives of innovation towards alternative frameworks, passing through neglected aspects and reactions to innovation.

\section{I.2.1 Part I: Problematic Frameworks and Narratives of Innovation}

The first part of the book reviews a few dominant narratives of innovation and demonstrates that they involve problematic frameworks. Part I represents an attempt to review the main dominant and taken-for-granted approaches regarding innovation. It pays special attention to the different value given to innovation compared to imitation.

Our story begins centuries ago when innovation was used not to discuss novelty but rather imitation. Innovation was a return to the purity or the origin of past ages. In Chapter 1 ('Why is imitation not innovation?'), Benoît Godin looks at Niccolo Machiavelli as an eminent example of this representation, and asks why such a meaning shifted over the twentieth century. Innovation theorists relegate to non-existence a series of concepts that are not within the semantic field of innovation. Such is the case with imitation. The chapter looks at when, how and why imitation, as an early meaning of innovation, was removed from the discourses on innovation. The chapter suggests that cultural values, disciplinary work, market ideology and semantics are key factors in explaining the neglect of imitation in discourses on innovation, and particularly in theories of innovation.

In Chapter 2 ("Innovation fads" as an alternative research topic to proinnovation bias: the examples of Jugaad and Reverse Innovation'), Gérald Gaglio observes the transformation of innovation into a business, and the flood of innovation-related pseudo-concepts and methods that compete to legitimize new truisms. He then focuses on the adjectives and attributes associated with innovation as a way to investigate initiatives that present themselves as innovative. The chapter presents these 'innovation fads' as a subject of investigation and a way of understanding innovations and their dissemination. In particular, the chapter looks at the case of 'frugal' innovation as a 'trending fashion' supposedly 'inclusive' of poor consumers, in particular Jugaad Innovation and Reverse Innovation. In the case of Reverse Innovation, there were active promotion, successful books 
with dramatic narrations and management review articles, in contrast to 'frugal innovation' coming from the world of non-governmental organizations (NGOs). The author shows that studies of 'innovation fads' have to consider both innovation and organization as two sides of the same coin.

In Chapter 3 ("Best practices" as mimesis? Innovation policies in peripheral countries'), Tiago Brãndao and Carolina Bagatolli explain that over recent decades, technological innovation has become the new mantra in the Science, Technology and Innovation Policy (STIP) of many countries, including the world's peripheral countries. The authors explore neoliberalism and deconstruction of the state and the ideals of rationalization and bureaucratization as the origin of best practices, as well as the idea that 'there is always a best model to follow'. This idea leads to isomorphic pressure for national STIP within peripheral countries to adopt best practices. The idea of the best model to follow also refers to the quest for authority and legitimacy of national STIP. All of this is evident when the authors look at the policy process (rationalities, main goals, policy mechanisms and legislation), which appear to be quite similar despite some degree of variation within the formal structures or regarding the historical backgrounds from country to country. The authors portray the best practices rhetoric (a 'pre-packaged plug' to address policy challenges) as an approach to policy formulation and implementation that promotes a desired effect in policy milieus by appealing to models and engendering a process of 'isomorphism' on the structures (institutions) and behaviours affecting national science policies. They observe that the reforms seen in the STIP of various Latin American and Iberian countries, creating an 'innovation culture' of entrepreneurship, are based on very similar discourses and incentives.

In Chapter 4 ('Innovation and the political state: beyond the myth of technologies and markets'), Sebastian Pfotenhauer and Joakim Juhl draw our attention to the recent surge in calls for a 'return' to the glorious era of state-led technology and innovation policy. They show that these calls are only superficially different from the way the state has been conceptualized as a hands-off funder-facilitator in previous times. They argue that this narrow framing not only fails to consider the transformative social and political implications of innovation but also renders the innovative state devoid of almost every function that make up statehood as a sociopolitical entity in common parlance - all but its facilitation of technology-based economic growth. Other state responsibilities like the expression of political will through collective decision-making, democratic representation, distributive justice or the guarantee of basic constitutional rights remain squarely outside mainstream innovation theory. Pfotenhauer and Juhl trace the origins of this impoverished framing of the state and 
its localization outside the innovation process to the 'technology-market dyad' - the notion that innovation plays out primarily between apolitical technologies and apolitical markets - and show how the innovation literature has perpetuated this conceptual model since Vannevar Bush's 1945 Science, the Endless Frontier. They contrast this framing with alternative theoretical approaches from Science and Technology Studies that theorize about the role of the state within innovation policy in a more holistic and inclusive fashion. In particular, they propose a co-productionist approach to innovation policy in which technoscientific and sociopolitical orders are treated as mutually constitutive and dependent.

\section{I.2.2 Part II: What is Left with the Pro-innovation Bias}

In Chapter 5 ('Moving towards innovation through withdrawal: the neglect of destruction'), Frédéric Goulet and Dominique Vinck go back to innovation scholars and dominant discourses to point out how these relegate destruction and withdrawal to secondary, collateral or unavoidable aspects of innovation processes. They qualify these dominant thoughts on innovation, whether classical or contemporary, and identify destruction, deadoption, exnovation and withdrawal as relevant phenomena. They then document a case study on the withdrawal of tilling in agriculture through which they propose an alternative way of thinking about innovation, showing that withdrawal is not as simple as it first appears; it is a complex process engaging strategic thinking and controversy, as well as creativity, invention and innovation. The chapter suggests that innovation through withdrawal is a growing phenomenon that requires empirical and theoretical investigation. The chapter also suggests that disciplinary bias, cultural values and ideology explain the neglect of destruction and withdrawal in discourses and theories about innovation.

In Chapter 6 ('Comparing two cases of outlaw innovation: file sharing and legal highs'), Johan Söderberg explores the opening up of innovation processes to users, in particular, user innovations unfolding on the 'wrong' side of the law, but from which firms profit. Focusing on this phenomenon, the chapter proposes understanding the innovation processes as inseparable from norms and value conflicts, and as a form of normative social action. What is evident with outlaw innovations would also be relevant for any innovation regardless of the legal status of users' practices. The argument is articulated through a comparison between two cases: computer hacking and file sharing, and the creation of novel psychoactive substances. The comparison underlines the role of enforcement regimes, public perceptions of transgressions, market structures, devoted users, intellectual property, the rate of innovation and the speed with which 
legislators can cope with users' involvement. Söderberg demonstrates how much industries are dependent on the legal grey zone as an incubator for innovation. He concludes with a series of questions and a call for more sociologically grounded studies of innovation.

In Chapter 7 ('Unattended consequences of innovation'), Karl-Erik Sveiby questions the general belief in the benefits of innovation for society, and the negligible consideration of undesirable consequences. Management/business literature dominates innovation research (how to control and accelerate innovation processes and diffusion in order to maximize corporate economic returns) and influences corporations, while Science and Technology Studies (STS) and Technology Assessment (TA) perspectives influence only government policy. The chapter bridges these discourses, examining the way two management research streams deal with consequences for recipients of change: the critical turn in organizational change management from a 'pro-change bias' to the more balanced view, and stakeholder theory with its ethical perspective on 'ultimate involuntary stakeholders' of change related to innovation. After a presentation of the STS/TA perspectives and the two management research streams, the chapter discusses these questions through a case study on financial innovation. The chapter shows that critical perspectives on financial innovation could have contributed much-needed, well-considered alternatives to the dominant pro-innovation biased discourse before the global financial crisis. Four questions for creating better balanced analysis are proposed.

\section{I.2.3 Part III: Reactions to Innovation}

In Chapter 8 ('Resistance as a latent factor of innovation'), Martin Bauer explores models of innovation (fluid dynamics and mass transfer, viral contamination, imitation) and their view on the social psychology of resistance (as an irrational expression of pathological technophobia or as amplified risk perception). Then he demonstrates that resistance to technoscientific mobilization enhances the self-awareness of the project organization. He suggests that this model of the functionality of resistance offers a more realistic account of the innovation process than any diffusion model. The chapter focuses on what motivates and enables resistance.

In Chapter 9 ('Socio-technical dynamics of counter-hegemony and resistance'), Hernan Thomas, Lucas Becerra and Santiago Garrido point to the fact that studies on innovation only consider a limited range of possibilities in terms of problem-solution dynamics, and neglect to analyse actions of sociotechnical resistance as well as other processes of technological change generated by NGOs, grassroots organizations, trade unions, indigenous communities and individual users. The chapter studies 
resistance to innovation in order to analyse it as a type of re-innovation. After a critical analysis of sociotechnical resistance approaches, the chapter introduces the concept of 'sociotechnical alliance' and focuses on the relationship between technology and ideology. It then analyses three case studies corresponding to three forms of sociotechnical resistance: 'resignification' of technologies, building of alternative technological systems and generation of counter-hegemonic public policies. It concludes by articulating a conceptual framework for the study of sociotechnical resistance.

In Chapter 10 ("No" and "slow" innovation strategies as a response to increased innovation speed'), Karl-Heinz Leitner also questions the argument according to which firms and countries must innovate continuously in order to survive and remain competitive. Some companies intentionally choose to escape from the race towards permanent and ongoing innovation, like the company that announces that it is proud of not having changed its products for many years. Such companies choose a 'non-innovation strategy', and have rationales for deliberately slowing down their innovation activities. Acceleration or deceleration of innovation also relate to controversies about innovation stagnation, diminishing returns from investments in $\mathrm{R} \& \mathrm{D}$, technological plateaus and degrowth. Furthermore, there is also a societal and political movement that strives for more sustainable methods of production and consumption. A slowing rate of innovation could be a result of a societal trend. The chapter studies the conditions under which companies may slow down the pace of innovation. It describes different strategies based on empirical findings reported in the literature, and suggests another way to think about innovation.

\section{I.2.4 Part IV: Alternative Frameworks}

The remaining chapters are all concerned with the search for alternative models and frameworks. In Chapter 11 ('Learning thanks to innovation failure'), Dominique Vinck begins with the observation that innovation is promoted as a solution to many problems and a generator of economic and social value. There is a focus on successful innovation, as if the motto were 'failure is not an option'. However, scholars also argue that most inventions do not become innovations, which seems scandalous, calling for improvements in the efficiency of innovation. The chapter points out that failure is considered only as a loss. The chapter first gives an account of the prevalent views of innovation as a search for success, as well as the few views regarding failure, and the absence of any conceptualization of failure dynamics and outcomes. Then the chapter documents a case study 
of failure through which it proposes an alternative way to think about innovation. The chapter offers a critique of current representations of innovation as success, and some avenues towards a way of thinking about failure and its diversity (disaster, minor failure, near-failure, unexpected results), its dynamics and its influence regarding political, social and managerial issues.

In Chapter 12 ('The economic rationality of NOvative behavior'), Carolina Cañibano, María-Isabel Encinar and Félix-Fernando Muñoz propose an alternative model based on the core argument that NOvation is a perfectly rational economic choice that may trigger structural change and development. To address the rationality of novation, the chapter argues that it is necessary to define an open economic rationality in which the objectives pursued by the agents that interact in the economic system are not identified a priori. This implies taking a step forward, from economics understood as a technology of choice to economics as a theory of the production of action. In this chapter, the authors discuss how this analytical step is made, and propose a broader framework that allows us to explain the transformations in socioeconomic systems that may follow from novation.

In Chapter 13 ('Regulatory enforcement as sociotechnical systems maintenance'), Lee Vinsel starts with the observation of a dual phenomenon regarding the automotive industry: the dramatization of novelty through annual model changes and marketing around demonstrating newness, versus the fact that mundane systems stay largely unaltered. In a single century, decisions-makers have reorganized society around the needs of automobile owners and the corresponding infrastructure (roads, parking lots, gas stations and so on) and developed standardization for both reliability and cost reduction according to the firm's needs, and for safety and emissions controls according to society's requirements. So a car-based landscape emerged, made up also of norms (law, codes, technical standards, quantitative criteria and tests) that shape sociotechnical arrangements. Vinsel argues that we should view the enforcement of standards as a form of system maintenance in the face of change, and focus on how standards are enforced and maintained, and on how sociotechnical orders are perpetuated through the proliferation of standards. After examining the dominance of invention and innovation in STS and the relative scholarly neglect of maintenance and repairs, he explores emerging maintenance studies. He describes the rise of automotive regulations in the United States, and uses a case study of an automotive recall to examine the work of regulatory enforcement and the maintenance of sociotechnical arrangements between organizations.

In Chapter 14 ('A discourse analysis of innovation in academic 
management literature'), Beata Segercrantz, Karl-Erik Sveiby and Karin Berglund explore the academic management discourse of innovation in high impact articles. They approach innovation as a discursive terrain where discourses compete to ascribe meanings to innovation. Since innovation is mainly constructed in management literature as a positive concept, they broaden the scope by analysing and problematizing the academic management discourse of innovation. The analysis shows that management research of innovation is self-referential; it primarily focuses on benefits for the innovating organization by promoting accelerated innovation, effective self-preserving practices and faith in the good end of innovation. What is constructed here is a potential self-reinforcing circle driving organizations to innovate faster and faster. They argue that research needs to acknowledge and explore what innovation leads to beyond the immediate economic interests of organizations. This would help scholars to identify blind spots, and to invite research that rejects the pro-innovation bias in order to extend research agendas to also include undesirable effects of innovation and possibilities to reduce them.

John Langrish, co-author of Wealth from Knowledge (1972), concludes the book with some personal reminiscences and views. In Chapter 15 ('Physics or biology as models for the study of innovation'), John Langrish describes debates on the nature of innovation and on methods for studying it. He was a participant in these debates some 40 years ago and he claims that they are relevant today. According to Langrish, these debates are an avenue for exploration of the differences between models inspired by classical physics and biology. Modern literature on innovation studies the subject by imitating classical physics, with stable entities and consistent causation. However, Langrish suggests that biology is more relevant for studying the complexities of innovation, the changes of entities over time, unpredictable dynamics and the emergence of new things (speciation). He frames a neo-Darwinian method of studying innovation with memes as imperfect replicators.

\section{I.2.5 Conclusion}

Finally, Benoît Godin and Dominique Vinck conclude ('Towards critical studies of innovation') with suggestions regarding the future. As the book has demonstrated, the dominant frameworks in terms of rational process and breakthrough are problematic because of what is left out. We suggest exploring phenomena that may appear irrational and alternative frameworks, and overcoming underlying political ideologies. We invite researchers to develop a research programme on Critical Studies of Innovation. We propose four avenues or approaches regarding the concepts used, the focus 
and the phenomena to be studied. We call for new definitions and models for innovation studies.

\section{NOTES}

1. For a similar view of the standard or 'rational model' of innovation, see Donald Schon: a goal-directed process, an orderly process, an intellectual process (Schon, 1967).

2. Novation is a term from the late Middle Ages that gave rise to novateur in French. According to an early English dictionary, novation means renewing, or making new (Phillips, 1658). A French dictionary of the time suggests, 'on ne dit pas innovateur: le mot usité est Novateur' ('we don't say innovateur: the commonly used word is Novateur') (Féraud, 1787). 'Ce mot d'inovateur n'est pas approuvé, on dit novateur' ('this word innovator is not approved, one says novator') (Richelet, 1680).

\section{REFERENCES}

Arthur D. Little Inc. (1965), Management Factors Affecting Research and Exploratory Development, Report to the US Department of Defense, Arthur D. Little Inc.

Bush, Vannevar (1945), Science: The Endless Frontier, reprinted in 1995, North Stratford: Ayer.

Edgerton, David (2008), From Innovation to Use: Ten Eclectic Theses on the Historiography of Technology, History and Technology, 16, 111-35.

Eyestone, Robert (1977), Confusion, Diffusion, and Innovation, American Political Science Review, 71 (2), 441-7.

Féraud, Jean-François (1787), Dictionnaire critique de la langue française, Marseille: Jean Mossy.

Godin, Benoît (2014), 'Innovation Studies': Staking the Claim for a New Disciplinary 'Tribe', Minerva, 52 (4), 489-95.

Godin, Benoit (2015a), Innovation Contested: The Idea of Innovation Over the Centuries, London: Routledge.

Godin, Benoît (2015b), Technological Change: What do Technology and Change Stand for? Project on the Intellectual History of Innovation, Working paper no. 24, INRS, Montreal.

Godin, Benoît (2016), Technological Innovation: On the Emergence and Development of an Inclusive Concept, Technology \& Culture, July, 57 (3), $527-6$.

Godin, Benoît (2017), Technological Change, or, STS before STS, Project on the Intellectual History of Innovation, INRS, Montreal.

Gold, Bela (1969), The Framework of Decision for Major Technological Innovation, in Kurt Baier and Nicholas Rescher (eds), Values and the Future: The Impact of Technological Change on American Values, New York: Free Press, pp. 389-430.

Holt, K. (1971), Social Innovation in Organizations, International Studies of Management \& Organization, 1 (3), 235.

Kimberly, John R. (1981), Managerial Innovation, in Paul C. Nystrom (ed.), 
Handbook of Organizational Design, London: Oxford University Press, pp. 84-104.

Knight, Kenneth E. (1967), A Descriptive Model of the Intra-firm Innovation Process, Journal of Business, 40, 478-96.

Langrish, John, Michael Gibbons, William G. Evans and Frederic Raphael Jevons (1972), Wealth from Knowledge: Studies of Innovation in Industry, London: Macmillan.

Morton, J.A. (1971), Organizing for Innovation: A Systems Approach to Technical Management, New York: McGraw Hill.

Noss, Theodore K. (1940), Resistance to Social Innovations as Found in the Literature Regarding Innovations which have Proved Successful, Dissertation submitted to the Faculty of the Division of the Social Sciences in candidacy for the degree of Doctor of Philosophy, Department of Sociology, Chicago, Il.

Phillips, Edward (1658), The New World of English Words, or, A general dictionary containing the interpretations of such hard words as are derived from other languages. . . together with all those terms that relate to the arts and sciences . . ..: to which are added the significations of proper names, mythology, and poetical fictions, historical relations, geographical descriptions of most countries and cities of the world . . / collected and published by E.P., London: Printed by E. Tyler for Nath. Brooke.

Richelet, Pierre (1680), Dictionnaire français, Geneva: Jean Herman Widerhold.

Rogers, Everett M. (1962), Diffusion of Innovations, New York: Free Press.

Rubenstein, Albert H., A. Chakrabarti and R. O'Keefe (1974), Final Report on Field Studies of the Technological Innovation Process, Evanston, IL: Northwestern University Press.

Schatzberg, Eric (2006), Technik Comes to America: Changing Meanings of Technology Before 1930, Technology and Culture, 47, 486-512.

Schon, Donald A. (1967), Technology and Change: The Impact of Invention and Innovation on American Social and Economic Development, New York: Delta Books.

SPRU (1972), Success and Failure in Industrial Innovation, Report on Project SAPPHO, London: Center for the Study of Industrial Innovation.

Stern, Bernhard J. (1937), Resistance to the Adoption of Technological Innovations, in US National Resources Committee (ed.), Technological Trends and National Policy, Washington, DC: Subcommittee on Technology, USGPO, pp. 33-69.

Utterback, James M., Thomas J. Allen, J. Herbert Hollomon and Marvin A. Sirbu (1976), The Process of Innovation in Five Industries in Europe and Japan, IEEE Transactions on Engineering Management, 23 (1), 3-9. 